\title{
Exploring Group Cooperation in the Provision of Public Goods
}

David Zetland*

Leiden University College, the Netherlands;

d.j.zetland@luc.leidenuniv.nl

\begin{abstract}
A novel version of a Voluntary Contribution Mechanism game tests how player cooperation responds to changes in incentives, i.e., payoffs that depend on performance relative to different reference groups. Cooperation is greatest when players are competing against players in other four-person groups, intermediate when competition is diffused, and lowest when players compete in a zero-sum game within their own group.
\end{abstract}

Keywords: Voluntary contribution mechanism; in-group/out-group comparisons; public goods; free-riding

JEL Codes: C72, C92, D71, H41, Q56

\section{Cooperation, Free Riding and the Environment}

How do you get thousands of college students to use less water in the middle of a drought when they pay nothing for it? In 2014, 2,100 students in 14 residential dormitories at the University of California, Merced, competed in a "water battle" to see which dorm could use the least water (Anderson, 2014). The battle reduced water consumption, incentivized leak repairs, and raised overall awareness of water

*I thank the Department of Agricultural \& Resource Economics at UC Davis and the Giannini Foundation for experimental funding. I thank Dustin Garrick, Jarek Kantorowicz, Stefan Kroll, Damian Park, Monticha Tanatammatid and Nikos 
conservation on a campus that sits in the middle of California's waterscarce Central Valley. This competition changed the incentives for long showers by aggregating individuals into teams that needed to cooperate to beat other teams. One team won, but all teams helped reduce campus water consumption.

Contrast this story to one in which individual farmers compete for water in a shared aquifer, thereby increasing total energy use and lowering local water security. Although groundwater users can achieve positive-sum gains by managing a shared aquifer to maximize sustainable yield over time, those gains will be lost if they try to out-pump each other. That is happening just down the road from UC Merced, where competition over agricultural groundwater has resulted in dry pumps, dropping ground levels and damage to local infrastructure (Goldenberg, 2015). This game of "all against all" could be stopped if farmers could collectively monitor and control groundwater use, but the provision of these public goods is blocked by non-cooperation and weak institutions. Every farmer complains about the others, but no farmer has been willing or able to shift from selfish to collective behavior.

This paper investigates how incentives can help or hinder the provision of public goods in an experimental setting. Public goods, like common-pool goods, are non-excludable in their provision and use, which means that they are vulnerable to free riding (taking benefits without paying costs) by some at the expense of others. Free riding undermines cooperation and contributes to the under-provision of public goods or over-appropriation of common-pool goods, both of which figure prominently in discussions of environmental management and sustainability (Ostrom et al., 1994).

The examples from the Central Valley concerned appropriation of common-pooled waters, but they also showed how internal norms or formal rules can create public goods that benefit everyone, i.e., the provision of organization for a "water battle" or lack of organization to avoid over-pumping groundwater.

This paper contributes to the literature on strategic behavior and the environment by exploring the impacts of structures and incentives

Zirogiannis for their comments on drafts of this paper as well as two very helpful referees and the editors for their generous attention. All remaining mistakes are mine. 
on the provision of public goods. It does so by comparing four versions of a Voluntary Contribution Mechanism (VCM) that produces a public good whose benefits are shared among players. In all treatments, players begin in a first stage in which their contributions to a VCM result in raw earnings that reflect a tension between free riding for individual gain versus cooperation to maximize group earnings. In the second stage, raw earnings are transformed into final earnings via a formula that depends on which of the four Treatment Comparison Groups (TCGs) applies to that game session. This two-step process makes it easier to answer the main research question, which is "how does cooperation change when the TCG changes?"

Skipping ahead for a moment, experimental results indicate that between-group competition leads to the greatest in-group - and thus overall - cooperation among players. This "beat the other team" treatment (similar to the water battle example) performed much better than the "beat your teammates" treatment (similar to the groundwater example) in which players competed for a fixed sum within their group of four. The beat-the-other-team treatment also had decent performance against treatments in which each player competed against all other players ("beat everyone else") or faced no competitive reference (the baseline, first-stage treatment).

Although the experiments were context-neutral, their VCM structures created similar incentives to those affecting environmental goods. In a direct application, these results might help one explore the provision of regulation or cooperation within an organization. In a "flipped" application, these results may contribute to efforts to prevent overappropriation. These mirrored incentives should make it easier to design or implement interventions. Farmers, for instance, might be rewarded (or penalized) for discharging less (or more) non-point pollutants than neighboring groups.

This paper develops as follows. The next section explains how free riding and cooperation affect environmental goods. The following section explains the experimental treatments, hypotheses and protocol. After reviewing results, the discussion section expands on the design and outcomes before suggesting some environmental applications in the conclusion. 


\section{Free Riding Reduces the Supply of Non-Excludable Goods}

Many economists work with excludable private and club goods that can be created, traded and consumed within a framework of property-rights and markets. That framework does not work very well for managing nonexcludable public and common-pool goods that are subject to free riding in provision and consumption respectively. In their analysis of nonexcludable goods, Ostrom et al. (1994) say a common-pool "situation" has turned into a "dilemma" when free riding leads to the suboptimal under-provision of a public good or over-appropriation from a commonpool good at the same time as institutional reform could conceivably improve matters. Their book is devoted to addressing these dilemmas (also known as open-access dilemmas) by understanding and changing institutions to reduce free riding. It is important to note that most of their analysis and suggestions apply to non-market settings where community or government power structures rely on non-cooperative or cooperative rules, respectively.

Most environmental problems can be traced to common-pool dilemmas, i.e., the under-provision or over-consumption of goods. A community that fails to contribute to public-good defenses or storage is vulnerable to flood or drought. Consumers who fail to internalize their negative externalities will pollute, and thus deplete, local or global environments. These suboptimal outcomes could be lessened or avoided if individuals gave less weight to their near-term, private payoffs and more weight to long-run, group payoffs.

The results of such rebalanced priorities can be seen in experimental or empirical settings where different behaviors interact. When free riders earn (or take) larger payoffs at the expense of others, they lower overall group efficiency. When cooperators share the burden of providing collective goods, they help increase average payoffs and thus increase group efficiency. In most situations, reciprocators magnify the actions of free riders or cooperators by matching negative or positive actions, thereby creating a positive feedback loop that drives outcomes towards negative or positive extremes respectively. Environmental parallels are clear. Cooperation to protect local ecosystems will, for example, result in greater shared benefits, and those benefits will encourage further cooperation to protect the resource.

These dynamics are present in many communities, each with their own level of cooperation and free riding in the provision of public 
goods and/or appropriation from common-pool goods. Although some might consider those dynamics and outcomes as exogenous and path dependent, there are many instances in which changes to incentive structures have altered environmental outcomes (Carson, 1962; Joskow et al., 1998; Schuerhoff et al., 2013; Wolsko et al., 2016). These examples justify research into the institutions and incentives affecting behavior.

\section{Designing Experiments to Understand Cooperation}

A VCM game recreates the incentives relevant to the provision of public goods because players know they can cooperate by contributing but free ride by holding back. A novel modification of this VCM design tests how (or if) behavior changes in each of four treatments that alter payoff functions by changing the TCG. In the first stage of all treatments, each group of four players plays a VCM game to determine its raw token earnings. In the VCM, a player loses 1.0 token for each token they contribute from their endowment to their group public good (GPG) and gains 0.5 tokens for each token contributed to their GPG by any player, i.e., a marginal per capita return, or MPCR, of 0.5 on contributions. In the second stage, the treatments differ in how they transform VCM earnings into final token earnings using a formula that varied by treatment. This two-stage format increases the probability that observed outcomes differ with the treatment rather than other variables because all players begin from the same first-stage foundation. The next Section ("Experimental Details") provides a precise description of each treatment, but here is a brief overview and motivation for testable hypotheses.

Treatment 1 (baseline) Final tokens equal raw tokens. Results in this baseline VCM case will reflect "typical" free-riding/cooperation behavior under incentives that reduce individual payouts with contributions to the GPG. Contributions and payouts in other groups do not affect this strategy. Although there is an incentive for players to cooperate in this repeated game to increase total payoffs (and thus individual payoffs) via strategies of reciprocation, backwards induction suggests that final-round free riding will lead to cooperation unraveling all the way to earlier rounds, i.e., a Nash equilibrium in which each player contributes nothing and all players earn their endowments. 
Treatment 2 (own group) Each group divides a fixed quantity of final tokens among its four members according to relative raw tokens, i.e., if one player has twice the raw tokens of another in the same group, the first player's final earnings are double the second player's earnings. Since each group's total earnings are fixed, incentives for cooperation are absent. This treatment has the same theoretical Nash equilibrium as Treatment 1, but actual contributions will be lower if boundedly rational or other non-equilibrium perspectives affect choices (Kahneman, 2011).

Treatment 3 (other groups) Final tokens depend on each player's raw earnings relative to members of other groups. Inside group incentives are the same as in Treatment 1, but final earnings rise as individual raw earnings exceed those of players in other groups. The theoretical outcome here - given the exogeneity of actions in other groups - is the same as in Treatment 1. Empirically, contributions will be higher if players change their focus from free riding within their group to cooperating to beat other teams. This change of focus is augmented by the extrinsic incentive of payoffs rising (within-group MPCR > 0.5) in groups producing a larger GPG than other groups.

Treatment 4 (all players) All players divide a fixed number of final tokens in proportion to individual raw earnings among all players. In addition to the same Nash equilibrium (contribute nothing), this treatment does not incentivize in-group cooperation as much as Treatment 3 nor discourage it as much as Treatment 2. Average cooperation will be higher than in Treatment 1 if players see cooperation within their group as a way to help themselves individually against players in other groups. Cooperation will be lower if players think the cap on total payouts limits the marginal return to cooperation and encourages them to grab a larger share of their group's GPG.

These four treatments explore different elements affecting VCM cooperation and outcomes. Although all treatments have a theoretical Nash equilibrium of zero contribution to the GPG, team identity or bounded rationality might lead to positive cooperation in all treatments (Akerlof and Kranton, 2000; Kahneman, 2011; Kurzban et al., 2001). 
The presence of tournament incentives, on the other hand, will reduce cooperation by rewarding players for relative rather than absolute earnings (Andreoni, 1995; Houser and Kurzban, 2002). These influences affect stage-two payoffs by varying the TCG and thus - via a single step of backwards induction - stage-one contributions to the public good. Taking as given the interdependence of the four players in each group in stage one, note that final payoffs depend on zero other players (if 20 in total for the session) in Treatment 1, three other players in Treatment 2, fifteen other players in Treatment 3 , and nineteen other players in Treatment 4.

More importantly, those other players are also collected in TCGs that affect aggregate dynamics. Treatment 1 provides a "plain vanilla" scenario testing cooperation (or lack thereof) in providing the public good. Treatments 2 and 3 add TCGs that might affect cooperation. Players in Treatment 2 are stuck in a zero-sum game within their groups (each an independent TCG) since a higher payoff to one member leaves less of the group's fixed total for the other three members. Treatment 3 inverts that scenario by rewarding (punishing) players within one group when other groups cooperate less (more). Treatment 4 shifts the focus from group performance to individual ranking by allocating shares from the fixed total according to a player's performance relative to the TCG of all other players.

These treatments recreate real-world incentive structures where communities depend on citizen cooperation to produce a public good that benefits all. Treatment 1 resembles the baseline case where cooperation (contribution) depends on intrinsic motivation. Treatment 2 recreates a zero-sum game with no incentive to cooperate - the case of winner-takes-all competitions. Treatment 3 creates incentives to cooperate within teams without addressing monitoring or shirking (Alchian and Demsetz, 1972; Berg et al., 1995). Treatment 4 creates a slightly stronger incentive to free ride by reallocating to those who earn (free ride) the most.

Other researchers have investigated the impacts of changing VCM incentives. Andreoni (1995) conducted a VCM experiment with a "Rank treatment" similar to Treatment 2 that was meant to push players to the Nash equilibrium of zero contributions. Rank players had the lowest contribution levels compared to his baseline version of Treatment 1 (a result confirmed by Houser and Kurzban (2002)'s enhanced 
version of Andreoni), but he did not test a version of Treatment 4 . Ule et al. (2009) made this comparison using a modified dictator-game to compare the effects of tournament incentives inside groups and across all players. They found that players competing within-group (Treatment 2) punish more and cooperate less than players competing across all groups (Treatment 4). These results suggest that it may be easier to affect cooperation than eliminate it (Anderies et al., 2011). Turning to in-group/out-group dynamics, Bornstein and Ben-Yossef (1994) find that players inside a group cooperate more if between-group conflicts exist, a result affirmed (and explored in detail) in the meta-analysis of in-group/out-group cooperation by Balliet et al. (2014), who conclude that in-group favoritism has a stronger impact on cooperation than out-group derogation. Bornstein et al. (2002) study the impact of these structures, finding that collective efficiency is higher with intergroup competition than without it, i.e., Treatment 3 relative to Treatment 1.

Although no paper covered all four treatments (this one may be the first), a casual summary of this literature suggests that cooperation will be lower in Treatments 2 and 4 than in Treatment 1 due to anticooperative and tournament incentives, respectively, while Treatment 3 should have more cooperation than Treatment 1 due to its stronger teamwork incentives. The following sections will explain how these expectations were rephrased as null hypotheses and tested.

\section{Experimental Details}

In each of four treatments, players contribute tokens to a public-goods account within each group. Given players indexed as individuals $(i \in$ $[1 \ldots h \ldots I])$ in groups $(g \in[1 \ldots k \ldots G]), p_{h, k}$ - the raw earnings for player $h$ in group $k$ - are:

$$
p_{h, k}=E-c_{h, k}+m \sum_{i=1 \ldots n} c_{i, k},
$$

where $E$ is each player's token endowment, $c_{h, k}$ is the token contribution of player $h$ in group $k$ to their GPG, $c_{i, k}$ are contributions from all players in group $k$ to their GPG, $n$ is the number of group members, and $m$ is the marginal per capita return (MPCR) to each token contributed 
to the GPG. For $0<m<1<m * n$, this is the usual linear public-goods game, with a Nash equilibrium of zero contributions by all and a social optimum where all players contribute their entire endowment.

These bounds are tested in each treatment, where the formula for converting raw earnings $\left(p_{h, k}\right)$ to final tokens $\left(\pi_{h, k}\right)$ differs. The Appendix reproduces the instructions explaining these payoff incentives to experimental participants.

\section{Treatment 1 (baseline)}

Player $h$ in group $k$ receives final token earnings $\pi_{h, k}$ equal to their raw tokens, i.e.,

$$
\pi_{h, k}=p_{h, k} .
$$

Total payments are not fixed, but each group's earnings are limited to a maximum of $m n E$.

\section{Treatment 2 (own group)}

A player's share of the fixed quantity of final tokens $(F)$ depends on their share of raw earnings, i.e.,

$$
\pi_{h, k}=F\left(\frac{p_{h, k}}{\sum_{i} \sum_{g=k} p_{i, g}}\right) .
$$

This is a pure in-group tournament structure. The Nash equilibrium has not changed compared to the baseline, but there is no social optimum (or, to be correct, each combination of contributions is a social optimum), since each group always earns - or divides $-F$.

\section{Treatment 3 (other groups)}

A player's final earnings relative to an arbitrary fixed "targeted earning" $(T)$ depends on their raw earnings relative to average raw earnings of players in other groups, i.e.,

$$
\pi_{h, k}=T\left(\frac{p_{h, k}}{\sum_{i} \sum_{g \neq k} p_{i, g} /(G-1) n}\right)=(G-1) n T\left(\frac{p_{h, k}}{\sum_{i} \sum_{g \neq k} p_{i, g}}\right) .
$$

Unlike the case for Treatments 2 and 4, total payouts in this treatment are not fixed. Although $T$ anchors earnings, uncertainty over the 
ratios of players' raw earnings means that total payments to players are also uncertain.

The Nash equilibrium prediction does not change - each player hopes that his group has a high contribution level but still has an incentive to contribute nothing. As in Bornstein and Ben-Yossef (1994), the desire for a group total higher than that of other groups does not change the individual's incentive to contribute nothing. That said, it is clearly better if players on other teams earn less.

\section{Treatment 4 (all players)}

A player's share of the total fixed quantity of final tokens $(G * F)$ depends on his raw earnings relative to all players, i.e.,

$$
\pi_{h, k}=G F\left(\frac{p_{h, k}}{\sum_{i} \sum_{g} p_{i, g}}\right) .
$$

Incentives to cooperate inside the group are stronger than in Treatment 2 but weaker than in Treatment 3 . Total payments are fixed in advance at $G F$.

\section{Sample Payoffs Among Treatments}

Table 1 illustrates how the formulas above convert the same set of contributions into final token earnings for each treatment, given $n=$ $4, G=4, m=0.5, E=50, T=75$ and $F=300$. Raw earnings are not shown, but players who receive feedback and are paid based on final tokens know that their raw earnings are only relevant insofar as they translate into final token earnings.

\section{Experimental Protocol}

In each of eight sessions, different sets of participants played an unrelated but similar public-goods game (Game 1) before playing the game discussed here (Game 2) on UC Davis computers running zTree software (Fischbacher, 2007). In each session, players in Game 1 are randomly reshuffled into new groups of four in Game 2 to break momentum. (There was no statistically significant correlation between Game 1 and Game 2 cooperation results across all sessions.) Players 
Table 1: A comparison of payoffs among treatments to Member $1\left(\pi_{1,1}\right)$ and Members 2-4 of Group $1\left(\pi_{2-4,1}\right)$ given 0 or 50 token contributions by Member 1 in Group 1 $\left(c_{1,1}\right)$, Members $2-4$ in Group $1\left(c_{2-4,1}\right)$, and the 12 other members of Groups 2-4 $\left(c_{1-4,2-4)}\right.$.

\begin{tabular}{ccccc}
\hline Contributions & \multicolumn{4}{c}{ Payoffs to $\pi_{1,1}, \pi_{2-4,1}$ in } \\
\cline { 2 - 5 }$c_{1,1}, c_{2-4,1}, c_{1-4,2-4}$ & T1 & T2 & T3 & T4 \\
\hline $0,0,0$ & 50,50 & 75,75 & 75,75 & 75,75 \\
$0,0,50$ & 50,50 & 75,75 & 38,38 & 43,43 \\
$0,50,0$ & 125,75 & 107,64 & 188,113 & 158,95 \\
$50,0,0$ & 25,75 & 30,90 & 38,113 & 35,106 \\
$50,50,0$ & 100,100 & 75,75 & 150,150 & 120,120 \\
$0,50,50$ & 125,75 & 107,64 & 94,56 & 97,58 \\
$50,0,50$ & 25,75 & 30,90 & 19,56 & 21,62 \\
$50,50,50$ & 100,100 & 75,75 & 75,75 & 75,75 \\
\hline
\end{tabular}

stayed in the same group for all eight periods of Game 2, anonymous and non-communicative.

Game 2 was designed and played in three rounds of eight periods each to allow a different treatment in the middle round (the first and third rounds used the same treatment), but that structure introduced noise into play (and the data), so this paper only reports results from the first round of eight periods Each of the four treatments was run twice with 16 or 20 players in the first round of eight periods, so there are 1,216 observations for 152 players. Results are reported below in descriptive terms and then via panel regressions testing the impact of treatment on contributions after controlling for the period of play and random effects by player.

In each session, players heard instructions for the relevant treatment (see Appendix) before starting play. In each of eight periods, players divided their endowment of 50 tokens between their private account and the GPG. Players had 40 seconds to make their initial contribution decision in period 1 and 20 seconds to decide in other periods. At the end of each period, players had 40 seconds to inspect their raw and final token earnings on the profit screen (see Appendix for examples). 


\section{Results}

Treatment effects are first tested by comparing mean player contributions with the GPG, by period. (Individual contributions are tested below.) The mean for each period is composed of 36 or 40 individual player contributions since each treatment was run twice with 16 or 20 players. Figure 1 and Table 2 show these means. From a descriptive perspective, mean player contributions are highest in Treatment 3 and progressively lower in Treatments 1, 4 and 2. Treatment 3 has the highest (or tied for highest) mean contribution in seven of eight periods. Treatment 2 has the lowest (or tied for lowest) mean contribution in seven of eight periods.

In two-sided pairwise $t$-tests comparing mean contributions by period (eight observations), Treatment 1 contributions are higher than those in Treatment $2(p<0.017)$, lower than those in Treatment $3(p<$ $0.023)$, and statistically similar in Treatment $4(p<0.167)$. In similar tests, Treatment 2 contributions are lower than those in Treatment 3

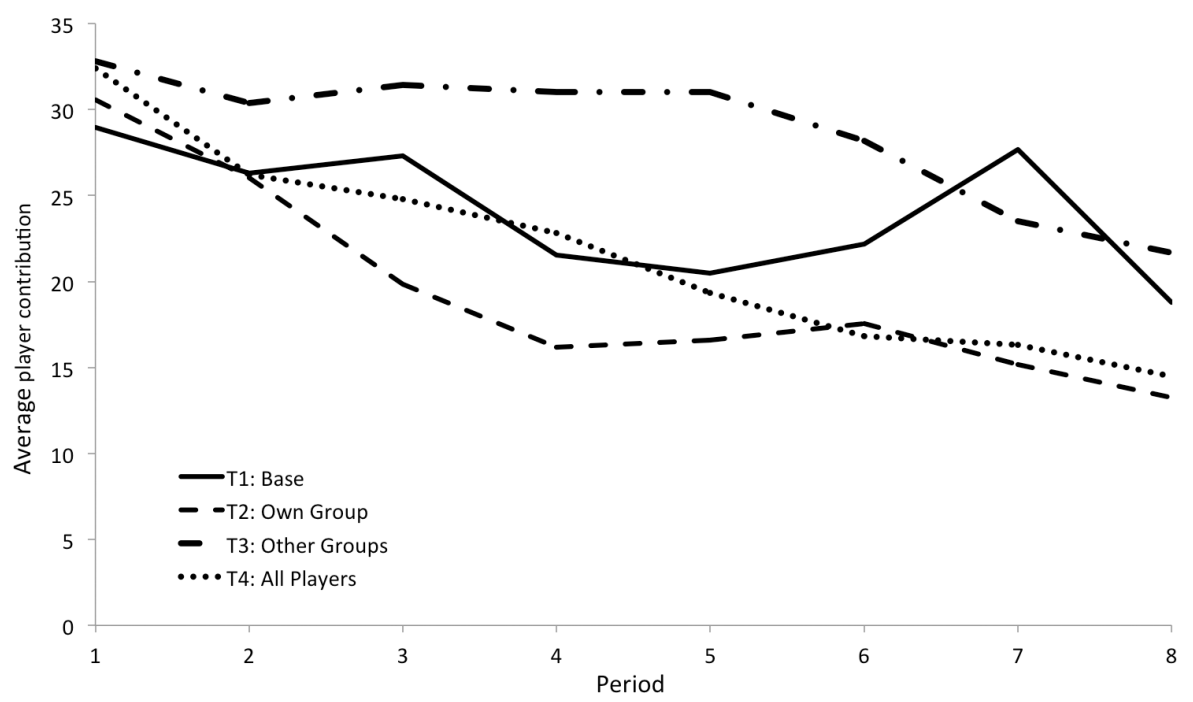

Figure 1: Although average player contributions to the group's public-goods account falls as sessions progress, the ordering of treatments by average contributions is reasonably stable. 
Table 2: Mean contributions per period, by treatment (each run twice) with the mean for all eight periods.

\begin{tabular}{lccccccccc}
\hline Treatment & 1 & 2 & 3 & 4 & 5 & 6 & 7 & 8 & Average \\
\hline 1 Baseline & 29 & 26 & 27 & 22 & 20 & 22 & 28 & 19 & 24.2 \\
2 Own group & 31 & 26 & 20 & 16 & 17 & 18 & 15 & 13 & 19.4 \\
3 Other groups & 33 & 30 & 31 & 31 & 31 & 28 & 24 & 22 & 28.8 \\
4 All players & 32 & 26 & 25 & 23 & 19 & 17 & 16 & 14 & 21.7 \\
\hline
\end{tabular}

Table 3: Panel regression (random-effects GLS) results comparing Treatment 3 (omitted dummy) with other treatments for 1,216 observations, controlling for characteristics of 152 players via random effects.

\begin{tabular}{|c|c|c|c|c|c|}
\hline Contribution & Coef. & Std. Err. & $p>|z|$ & 95\% Conf. & Interval \\
\hline$\overline{\text { Period }}$ & -1.77 & 0.16 & 0.00 & -2.09 & -1.45 \\
\hline Treatment 1 & -4.60 & 3.27 & 0.16 & -11.02 & 1.81 \\
\hline Treatment 2 & -9.35 & 3.19 & 0.00 & -15.61 & -3.09 \\
\hline Treatment 4 & -7.11 & 3.19 & 0.03 & -13.36 & -0.85 \\
\hline Constant & 36.74 & 2.43 & 0.00 & 31.98 & 41.51 \\
\hline$R^{2}(\mathrm{c}$ & 0.08 & & $\chi^{2}(4$ & 126.82 & $=0.00)$ \\
\hline
\end{tabular}

$(p<0.001)$ or Treatment $4(p<0.036)$. In the last pairwise comparison, Treatment 3 contributions are higher than those in Treatment $4(p<$ 0.036). In sum, mean contributions in Treatment 3 are higher than in statistically similar Treatments 1 and 4, both of which are statistically higher than mean contributions in Treatment 2.

Regression analysis allows a deeper look into the data, via a panel model that regresses contribution on period and dummies for treatment, controlling for random effects by player. Treatments were compared by rotating through the omitted treatment dummy to examine their relative impacts. Table 3 shows the output for the most relevant comparison of Treatment 3 to other treatments. The results allow us to reject the null that Treatment 3 has the same impact on contributions as Treatment 4 or 2 , but not for Treatment 1 . Although the estimated coefficients from 
the regressions match the averages in Table 2 in relative magnitudes, the coefficients are only significant in the comparison of Treatment 3 with Treatments 4 and 2 . We cannot reject the null that Treatment 1 has the same impact as Treatment 3.

\section{Discussion}

Taken together, these results indicate that players in a public-goods game cooperate more when their payoffs depend on their earnings relative to players in other groups (Treatment 3) rather than in relation to those of other players (Treatment 4) or players in their own group (Treatment 2). Although there was not enough data to separate the effects of Treatments 3 and 1 , the coefficients, averages and $t$-tests all lean in the direction of better cooperation results in Treatment 3. This trend is supported by looking at total contributions (i.e., "aggregate cooperation") for all players in all eight periods. In comparison to Treatment 3 (100 percent), contributions in Treatments 1, 4 and 2 were only at 84, 84 and 75 percent of Treatment 3's level, respectively. A statistical test comparing total contributions in the sample estimates that Treatment 3 would have higher total contributions in the population $(p<0.05)$ than the other three treatments would (Treatments 1, 2 and 4 are statistically similar in contribution totals).

The zero-sum incentive structure in Treatment 2, which led to the least cooperation, suggests that a scheme dividing a fixed reward within a team may lead to poor cooperation and outcomes. The value of the opposite recommendation - rewarding a team for beating another team on progress towards a clear target — is oppositely positive, as Treatment 3 had the highest cooperation. That result may have reflected the potential to increase total payoffs via cooperation, but the same incentive existed in Treatment 1, which may explain its statistically similar regression performance in comparison with Treatment 3.

\section{Conclusion}

This paper used four experimental treatments to investigate how changes in incentives affected behavior in a Voluntary Contribution Mechanism 
(VCM), or public goods, game. The greatest VCM cooperation resulted when players were rewarded for earning more than players in other groups, just as the lowest cooperation resulted from rewarding players who beat others in their own group. These results suggest that it may be easier to promote cooperation in providing public goods by encouraging teams to beat other teams rather than encouraging cooperation within a team.

Taking the basic incentives of a public goods game as a baseline (i.e., an incentive to free ride), these results indicate how to restructure incentives to improve cooperation in restoring ecosystems by promoting cooperation and suppressing free riding. The "Adopt a Highway" programs popular in the U.S. replace bureaucratic cleaning schedules with competition among teams responsible for keeping their "share" of the highway clean. The success of the $\mathrm{SO}_{2}$ cap and trade market can be traced to each polluter's incentive to reduce emissions faster than others in order to collect financial and reputational rewards (Schmalensee and Stavins, 2013).

These experimental results are congruent with known successes yet helpful in exploring different models affecting experimental cooperation in the provision of public goods. These incentive structures should be explored in the field with pilot projects to see if these results are robust.

\section{Appendix: Experimental Instructions}

\section{General Instructions}

(1) Welcome. We are starting now.

(2) Please turn off your cell phones.

(3) Does anyone have questions about the Bill of Rights or Consent Form? [WAIT]

(4) Please sign the bill of rights and both copies of the consent form. (The extra copy is for you to keep.)

(5) Please put all forms where I can co-sign and collect them during the experiment. 
(6) Today you will play two games-each more than once.

(7) Your earnings depend on how well you play the games.

(8) Your decisions and earnings will be anonymous. You will be identified by the number on the front of your folder. When we begin, you will enter the folder number into the computer.

(9) In all games, we use "tokens" for game money. The value of a token in real money is different in each game. You will learn the value before you begin each game.

(10) After the games, we will calculate and distribute earnings, in cash, in envelopes marked with your folder number. A research foundation has provided the funds for this study.

(11) Please stay silent throughout this experimental session and keep your attention on your own computer.

(12) Please raise your hand if you have a question. I will answer questions individually.

(13) Please take out the pink sheet, marked "Game 1" and close your folder until I tell you to open it again.

(14) Please read along with me. 


\section{Game 1 Instructions}

[NB: These results are not discussed in this paper]

This is a game of group and individual investment behavior.

- You are in a group of 4 with 3 others, chosen at random.

- You have an endowment of 50 tokens to invest. Others have the same endowment.

- You invest your tokens in the Individual Exchange and the Group Exchange.

- Your earnings depend on how you and your group invest tokens.

- 50 tokens $=\$ 1.00$.

Every token you invest in the Individual Exchange returns one token in earnings to you only.

Every token you invest in the Group Exchange returns 0.5 tokens in earnings to every member of your group, including yourself. It does not matter who invests in the Group Exchange - everyone gets a return from every token invested in the Group Exchange, whether or not they invested.

Your task is to maximize your earnings by choosing how many of your tokens to invest in the Group Exchange. (Remaining tokens go to the Individual Exchange.) Examples:

\begin{tabular}{lccc} 
& 1 & 2 & 3 \\
\hline Your Group Exchange investment & 0 & 50 & 30 \\
Your Individual Exchange investment & 50 & 0 & 20 \\
\hline If others' Group Exchange investments total & 90 & 110 & 0 \\
$\ldots$. total Group Exchange investment is ... & $0+90=90$ & $50+110=160$ & $30+0=30$ \\
\cline { 2 - 4 }$\ldots$ and everyone's Group Exchange return is & $90 / 2=45$ & $160 / 2=80$ & $30 / 2=15$ \\
\hline Your total earnings (in tokens) are & $50+45=95$ & $0+80=80$ & $20+15=35$
\end{tabular}

\section{Game Timing}

(1) All members of your group start with a simultaneous investment in the Group Exchange (Round 1). Click "Continue" after you enter your choice. You only have 20 seconds to click. A countdown clock is in the top-right corner of your screen. 
(2) In Round 2 and thereafter, you will (one person at a time) see the TOTAL investment in the Group Exchange. You will change or confirm your Group Exchange investment and click "Continue". You only have 10 seconds to click. If you take too long, your choice does not change.

(3) The opportunity to see the total and change/confirm passes from person to person in your group for an unknown, random number of rounds until the game ends, and all investments are final. You will have at least one opportunity to change/confirm your investment. Although you must wait while the decision passes around your group, try to pay attention so as to not to miss your turn.

(4) When each game ends, you will see your investment, the total investment in the Group Exchange, your earnings from the current game, and your cumulative earnings.

(5) When the game repeats, players are randomly reshuffled into new groups and the final round changes to a new, random number.

(6) We will begin now. The first thing you will do is enter your Folder Number. 


\section{Game 2 Instructions}

[NB: The game was originally played for 24 periods with the first treatment played for 8 periods, a different treatment for 8 periods, and the first treatment again for 8 periods. This design was faulty, as it introduced "contamination" (bias and noise) into the middle periods and final periods. Although results in periods 17-24 did not contradict results in periods $1-8$, those results are dropped to avoid bias.]

As in Game 1, you divide 50 tokens between the Individual and Group Exchanges. Game 2 differs from Game 1 in these ways:

(1) We will play two versions of this game.

(2) You will be in the same group of four throughout this game.

(3) The timing is thus:

(a) All members of your group make a simultaneous investment in the Group Exchange.

(b) The game ends, and you see your results.

(c) The game repeats.

(d) After 8 periods, we play a different version for 8 more periods. We then play the first version again, for 8 more periods. (24 periods total).

(e) You are in the same group with the same players for all 24 periods.

(f) For each version, you have 40 seconds to make your decision in the first period only; in other periods, you have 20 seconds. (As usual, hit the OK button to record your choice.)

(4) You earn Raw Tokens from the Individual and Group Exchanges (as before). Raw tokens are adjusted according to the version of the game [the following pages describe each of the four versions] we are playing to get Final Tokens. I'll explain this in a minute.

(5) 50 Final Tokens $=\$ 0.20$. 


\section{Version: No Change [Treatment 1]}

Say that you make the same contributions in the same way as in the previous game, for example:

\begin{tabular}{lcc}
\hline Your Group Exchange (GE) investment & 32 & 0 \\
Your Individual Exchange investment & 18 & 50 \\
\hline GE investments from others in your group & 57 & 90 \\
$\ldots$. total GE investment for your group is ... & $32+57=89$ & $0+90=90$ \\
\cline { 2 - 3 } ... and GE return to members of your group is & $89 / 2=44.5$ & $90 / 2=45$ \\
\hline Your raw earnings (in tokens) are & $18+44.5=62.5$ & $50+45=95$ \\
\hline
\end{tabular}

\section{Modification}

None - your raw token earnings and final token earnings are the same, for example, you get 62.5 (or 95) final tokens.

\section{Screenshot of Profit Calculation}

Your contribution to the Group Exchange

Total contributions in your group to the Group Exchange

Your raw earnings

Your final earnings

Your cumulative final earnings 


\section{Version: Own Group [Treatment 2]}

Say that you make the same contributions in the same way as in the previous game, for example:

\begin{tabular}{lcc}
\hline Your Group Exchange (GE) investment & 32 & 0 \\
Your Individual Exchange investment & 18 & 50 \\
\hline GE investments from others in your group & 57 & 90 \\
$\ldots$. total GE investment for your group is ... & $32+57=89$ & $0+90=90$ \\
\cline { 2 - 3 } ... and GE return to members of your group is & $89 / 2=44.5$ & $90 / 2=45$ \\
\hline Your raw earnings (in tokens) are & $18+44.5=62.5$ & $50+45=95$ \\
\hline
\end{tabular}

\section{Modification}

Each group shares 300 final tokens according to players' raw token earnings. Your final earnings depend on your raw earnings relative to others in your group. For example:

\begin{tabular}{lcc}
\hline Your raw earnings (in tokens) & 71 & 71 \\
Your group's total raw earnings & 306 & 262 \\
\hline Your share of your group's total & $71 / 306=23.2 \%$ & $27.1 \%$ \\
\hline Your final earnings (in tokens) & $23.2 \% * 300=69.6$ & 81.3 \\
\hline
\end{tabular}

\section{Screenshot of Profit Calculation}

Your contribution to the Group Exchange $\quad 32$

Total contributions in your group to the Group Exchange $\quad 106$

Your raw earnings

Total raw earnings (your group)

Your raw earnings as $\%$ of your group's raw earnings

Your final earnings (your $\%$ *300)

Your cumulative final earnings 


\section{Version: People in Other Groups [Treatment 3]}

Say that you make the same contributions in the same way as in the previous game, for example:

\begin{tabular}{lcc}
\hline Your Group Exchange (GE) investment & 32 & 0 \\
Your Individual Exchange investment & 18 & 50 \\
\hline GE investments from others in your group & 57 & 90 \\
$\ldots$. total GE investment for your group is ... & $32+57=89$ & $0+90=90$ \\
\cline { 2 - 3 }$\ldots$ and GE return to members of your group is & $89 / 2=44.5$ & $90 / 2=45$ \\
\hline Your raw earnings (in tokens) are & $18+44.5=62.5$ & $50+45=95$ \\
\hline
\end{tabular}

\section{Modification}

"Targeted" individual earnings are 75 tokens, but you can get more if your raw earnings relative to players in other groups (not your own group) are higher — or less if your relative earning are lower. For example:

\begin{tabular}{lcc}
\hline Your raw earnings & 91.0 & 91.0 \\
Average for players in other groups & 69.7 & 53 \\
\hline Your earnings vs. average player in other groups & $91 / 69.7=130.6 \%$ & $179 \%$ \\
\hline Your final earnings & $130.6 \% * 75=98$ & 135 \\
\hline
\end{tabular}

\section{Screenshot of Profit Calculation}

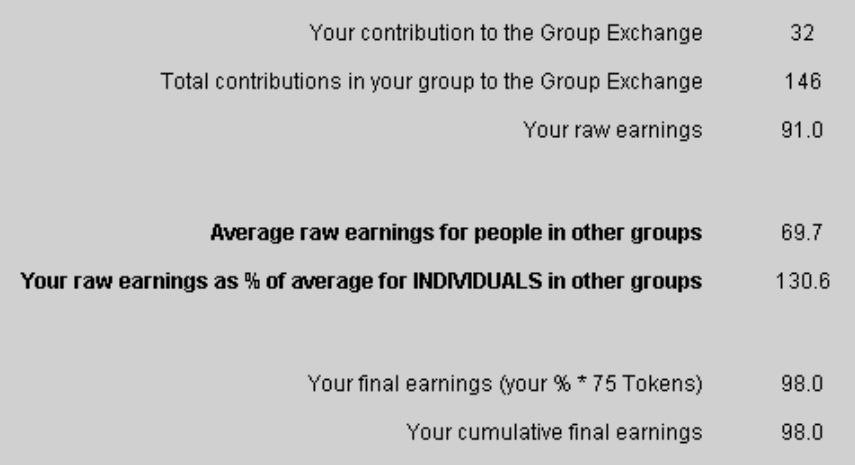




\section{Version: All Players [Treatment 4]}

Say that you make the same contributions in the same way as in the previous game, for example:

\begin{tabular}{lcc}
\hline Your Group Exchange (GE) investment & 32 & 0 \\
Your Individual Exchange investment & 18 & 50 \\
\hline GE investments from others in your group & 57 & 90 \\
... total GE investment for your group is ... & $32+57=89$ & $0+90=90$ \\
\cline { 2 - 3 }$\ldots$ and GE return to members of your group is & $89 / 2=44.5$ & $90 / 2=45$ \\
\hline Your raw earnings (in tokens) are & $18+44.5=62.5$ & $50+45=95$ \\
\hline
\end{tabular}

\section{Modification}

The quantity of final tokens available to all players is fixed at 1,200 for 16 players (or 1,500 for 20 players). Your final earnings rise (or fall) as your share of total raw earnings rises (or falls). For example:

\begin{tabular}{lcc}
\hline Your raw earnings & 42 & 42 \\
Raw earnings, 16 players & 1,150 & 743 \\
\hline Your share of total & $42 / 1150=3.7 \%$ & $5.7 \%$ \\
\hline Your final earnings & $3.7 \% * 1,200=43.8$ & 67.8 \\
\hline
\end{tabular}

\section{Screenshot of Profit Calculation}

$\begin{array}{rr}\text { Your contribution to the Group Exchange } & 32 \\ \begin{array}{r}\text { Total contributions in your group to the Group Exchange } \\ \text { Your raw earnings }\end{array} & 48 \\ \text { Total raw earnings } & 1150.0 \\ \text { Your raw earnings as \% of all raw earnings } & 3.7 \\ \text { Total Final Tokens Available } & 1200 \\ & 43.8 \\ \text { Your final earnings (your \% * Total Final Available) } & 43.8 \\ \text { Your cumulative final earnings }\end{array}$




\section{References}

Akerlof, G. A. and R. E. Kranton (2000), "Economics and Identity", Quarterly Journal of Economics, 115(3), 715-53.

Alchian, A. A. and H. Demsetz (1972), "Production, Information Costs, and Economic Organization", American Economic Review, 62(5), 777-95.

Anderies, J. M., M. A. Janssen, F. Bousquet, J.-C. Cardenas, D. Castillo, M.-C. Lopez, R. Tobias, B. Vollan, and A. Wutich (2011), "The Challenge of Understanding Decisions in Experimental Studies of Common Pool Resource Governance", Ecological Economics, 70(9), 1571-9.

Anderson, L. (2014), "Students Battle for Sustainability Supremacy, UC Merced University News, 1 Oct", Accessed 20 Feb 2017 at http: //www.ucmerced.edu/news/2014/students-battle-sustainabilitysupremacy.

Andreoni, J. (1995), "Cooperation in Public-Goods Experiments: Kindness or Confusion?", American Economic Review, 85(4), 891-904.

Balliet, D., W. Junhui, and C. K. De Dreu (2014), "Ingroup Favoritism in Cooperation: A Meta-Analysis", Psychological Bulletin, 140(6), 1556-81.

Berg, J., J. Dickhaut, and K. McCabe (1995), "Trust, Reciprocity, and Social History", Games and Economic Behavior, 10(1), 122-42.

Bornstein, G. and M. Ben-Yossef (1994), "Cooperation in Intergroup and Single-Group Social Dilemmas", Journal of Experimental Social Psychology, 30(1), 52-67.

Bornstein, G., U. Gneezy, and R. Nagel (2002), "The Effect of Intergroup Competition on Group Coordination: An Experimental Study", Games and Economic Behavior, 41(1), 1-25.

Carson, R. (1962), Silent Spring, Houghton Mifflin, New York.

Fischbacher, U. (2007), "z-Tree: Zurich Toolbox for Ready-made Economic Experiments", Experimental Economics, 10(2), 171-8.

Goldenberg, S. (2015), "The Central Valley is Sinking: Drought Forces Farmers to Ponder the Abyss", The Guardian, 28 Nov.

Houser, D. and R. Kurzban (2002), "Revisiting Kindness and Confusion in Public Goods Experiments", The American Economic Review, 92(4), 1062-9. 
Joskow, P. L., R. Schmalensee, and E. M. Bailey (1998), "The Market for Sulfur Dioxide Emissions", American Economic Review, 88, 669-85. Kahneman, D. (2011), Thinking, Fast and Slow, Farrar, Straus and Giroux, New York, NY.

Kurzban, R., J. Tooby, and L. Cosmides (2001), "Can Race be Erased? Coalitional Computation and Social Categorization", Proceedings of the National Academy of Sciences, 98(26), 15387-92.

Ostrom, E., R. Gardner, and J. Walker (1994), Rules, Games, and Common-Pool Resources, Ann Arbor Books, Ann Arbor, MI.

Schmalensee, R. and R. N. Stavins (2013), "The $\mathrm{SO}_{2}$ Allowance Trading System: The Ironic History of a Grand Policy Experiment", Journal of Economic Perspectives, 27(1), 103-21.

Schuerhoff, M., H.-P. Weikard, and D. Zetland (2013), "The Life and Death of Dutch Groundwater Tax", Water Policy, 15(6), 1064-77.

Ule, A., A. Schram, A. Riedl, and T. N. Cason (2009), "Indirect Punishment and Generosity Toward Strangers", Science, 326(5960), 17014.

Wolsko, C., H. Ariceaga, and J. Seiden (2016), "Red, White, and Blue Enough to be Green: Effects of Moral Framing on Climate Change Attitudes and Conservation Behaviors", Journal of Experimental Social Psychology, 65, 7-19. 